\title{
Factors Affecting the Use of Information Systems in Hybrid Models
}

\author{
Dwi Yuniarto ${ }^{1}$, M Agreindra Helmiawan ${ }^{2}$, Dani Indra Junaedi ${ }^{3}$, Asep Saeppani ${ }^{4}$, Yan Yan \\ Sopiyan $^{5}$ \\ \{duart0@stmik-sumedang.ac.id ${ }^{1}$, agreindra@stmik-sumedang.ac.id ${ }^{2}$, dani@stmik-sumedang.ac.id ${ }^{3}$, \\ saeppani@stmik-sumedang.ac.id ${ }^{4}$, yanyan@stmik-sumedang.ac.id $\left.{ }^{5}\right\}$
}

STIMIK Sumedang, Angkrek Situ 19 Sumedang West Java, Indonesia ${ }^{1}$

\begin{abstract}
The hybrid model has helped researchers solve problems found. In studies that measure the use of information systems, mixed models are very effective to use. Apart from the hardware and software side, a special hybrid model for measuring the use of information systems is also used for measurement from the user side. This study combines two models that are used to determine what factors are related to the readiness and usability of the use of information systems. The results of this study there are factors that influence the use of information systems, namely: innovation on efficiency, ease of learning about system usability, optimism on efficiency, optimism on efficiency, optimism on reliability, and optimism on satisfaction. The researcher assessed that the use of information systems ensured that innovation and optimism were important in using information systems. To further strengthen this research, of course, other studies must try to apply it to different objects with different characteristics of respondents' profiles. The profile of respondents is very important and influences the results, so it is recommended to consider the selection of respondents. Further research needs to be done again, in the hope of improving the model so that it makes a major contribution to the world of research.
\end{abstract}

Keywords: Mixed Models, Information System, Respondent

\section{Introduction}

The phenomenon of administrative presence for the Civil Servant (CS) in Indonesia some time ago using fingerprint, now the Government changes the policy by applying the presence of selfie method with the aim to better increase CS discipline and facilitate monitoring and evaluation regarding the presence of the CS.

The problem arises when users, namely the CS do not all have smartphones and not all are used to using smartphones. According to research that has been done, smartphone use can increase the activity of an organization [1-4]. On the other hand, it is strengthened by research on the use of Information Technology which is very important for the development of an organization [5]. So that researchers assume that an information system is acceptable to use, one of which can be measured from User Experience in accordance with the problems mentioned.

The purpose of this study is to measure the extent of Readiness and Usability of the CS presence system in Indonesia. The researcher used a combination of Readiness and Usability models [6] to measure it. 
This research consists of several stages. First, researchers conduct a study of problems to determine solutions and motivations and are supported by the literature review. Second, researchers determine the research method used to be able to help the process of answering the problems that occur. Third, the researchers elaborated on the results and discussion regarding the answer process assisted by combining Readiness and Usability models. Finally, the researcher conveys conclusions and suggestions for future development.

\section{Literature Reviews}

Research on attendance systems has produced many positive contributions to organizations and science. Very rapid changes, especially in the media used, make many alternative choices for implementing them in several organizations. Pattern recognition is one of media that has used it for a long time in several organizations, considering that the attendance system uses fingerprints that are difficult to represent [7-9]. Another alternative choice is to use Face Recognition to overcome problems in the attendance system, where users will find it difficult to cheat in terms of attendance [7, 10-12].

The use of Face Recognition in the attendance system includes using smartphone assistance to help users report their attendance activities through self-implemented applications in West Java Province with reference to Minister of Education and Culture Number 10 of 2018 concerning Technical Guidelines for Distribution of Professional Allowances, Special Objectives, and Additional Income for Regional Civil Servant Teachers.

To measure the readiness and usefulness of the application of the attendance system, the model resulting from the merger of two models is used, namely Readiness and Usability models [6]. The Readiness model is a model used to measure the level of readiness in the use of an information system $[13,14]$, considering the application of information systems needs some consideration that has to do with decision making through variables such as Optimism, Innovation, Discomfort, and Insecurity $[13,14]$.

The variable in the usability model is used as the dependent variable used to measure Learnability, Efficiency, Memorability, Reliability, and Satisfaction [15] to help answer the problems presented in Introduction regarding system usage issues. 


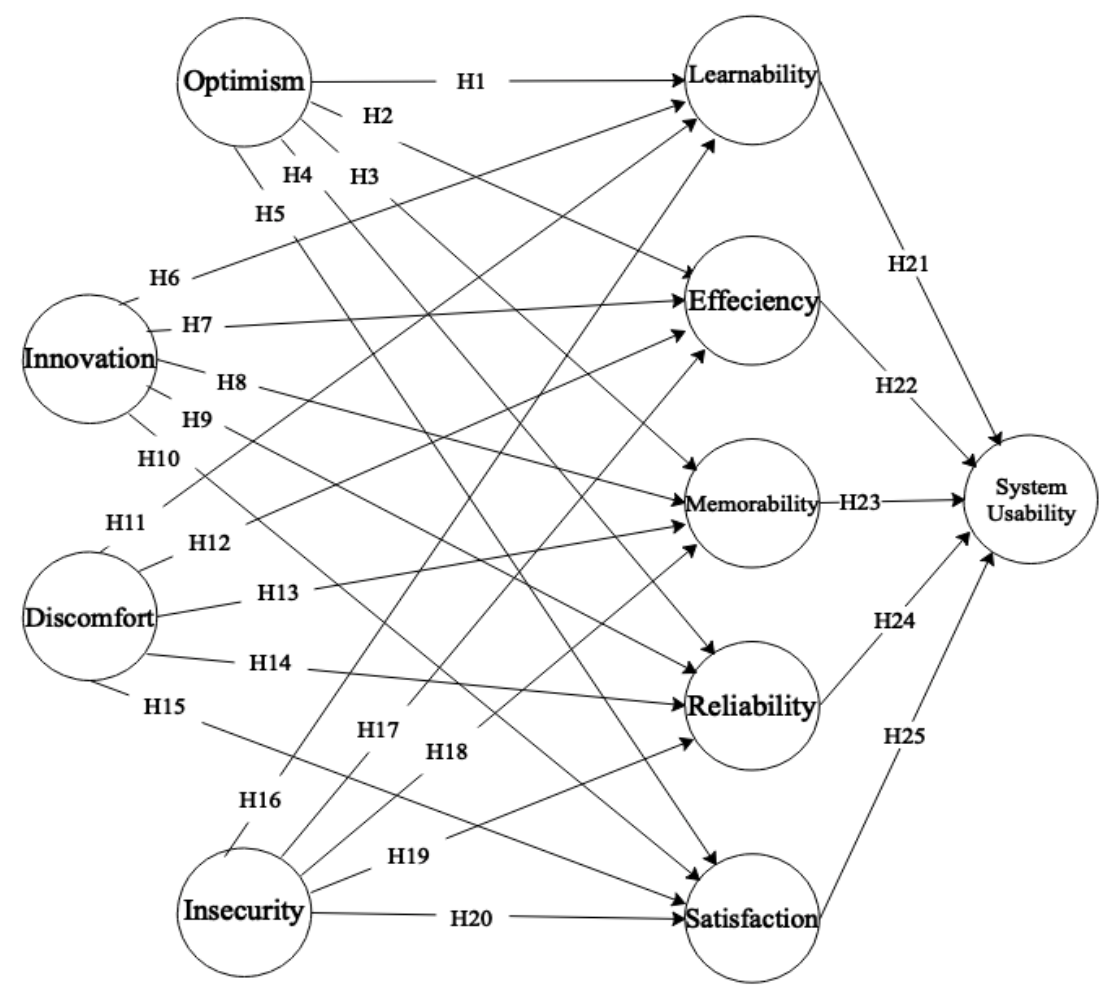

Figure 1. Research model [6]

The researcher distributed 28 copies of the questionnaire, which was distributed based on the experience of the respondent's profile. Distribution of questionnaires is done through Google Forms. The researchers processed the data collected using SmartPLS 3.2.7 Regarding the amount of data, the PLSSEM method was then used in the analysis phase using SmartPLS 3.2.7 to perform indicators of reliability, reliability of internal consistency, convergent validity, and assessment of discriminant validity. 
Table 1. List of Variables and Indicators

\begin{tabular}{lll}
\hline Variable & List of Indicators & References \\
\hline $\begin{array}{l}\text { Optimism } \\
\text { Innovation }\end{array}$ & $\begin{array}{l}\text { Ease, connectivity, efficiency, effectiveness, productivity } \\
\text { Problem-solving, independence, challenges, stimulation, } \\
\text { competitiveness }\end{array}$ & {$[13,16-20]$} \\
Discomfort & $\begin{array}{l}\text { Complexity, difficulty, dependence, lack of support, } \\
\text { inaccuracy }\end{array}$ & {$[13,16-20]$} \\
Insecurity & Failures, threats, reduce interactions, disturbances, doubts & {$[13,16-19,24]$} \\
Learnability & Ease of use, simplicity & {$[25]$} \\
Efficiency & Effective, fast, efficiency & {$[25]$} \\
Memorability & Understanding, functionality, comfort & {$[25]$} \\
Reliability & Availability, protection, maintenance, accuracy & {$[13,14,25-27]$} \\
Satisfaction & Clear, easy, satisfaction, right & {$[25]$} \\
System & Clear, pleasant, probable, hopeful, joyful & {$[25]$} \\
Usability & & \\
\hline
\end{tabular}

Table 2. List of questions in the questionnaire [6, 28]

\begin{tabular}{ll}
\hline Code & \\
\hline OPT1 & This system is free of obstacles, difficulties, and problems \\
OPT2 & The system can be easily connected with other systems \\
OPT3 & The system operates in minimal resources \\
OPT4 & The system operates in maximum output \\
OPT5 & This system can operate efficiently and effectively \\
INV1 & A system is a problem-solving tool for users \\
INV2 & The system helps users to be free of control/influence \\
INV3 & The system supports users to achieve goals in difficult situations or problems \\
INV4 & The system encourages users to reach the destination \\
INV5 & The system supports users to be more successful than their competitors \\
DCF1 & The system confuses users in their operations \\
DCF2 & The system cannot be operated easily \\
DCF3 & The system cannot be operated freely \\
DCF4 & The system is operated without full support operation \\
DCF5 & The system is not in accordance with the development plan \\
ISC1 & The system is not successfully operated in accordance with the development plan \\
ISC2 & The system is in a situation that can cause danger or danger \\
ISC3 & The system makes users less interacting \\
ISC4 & The system makes users become unfocused with their interests \\
ISC5 & This system is doubtful to use \\
LRN1 & This system is easy to use \\
LRN2 & The system is very simple \\
EFC1 & The system completes working effectively \\
EFC2 & The system quickly completes work \\
EFC3 & The system completes work efficiently \\
MMR1 & Information in this SI is easy to understand \\
MMR2 & Their commands are aligned with certain functions \\
MMR3 & There is an interface hierarchy that is easy to understand \\
RLB1 & The system is always available to operate when needed \\
RLB2 & The system is protected from physical access from non-authoritative rights \\
RLB3 & This system is easy to maintain \\
RLB4 & System processing is complete, accurate and timely \\
STF1 & In this SI, the information provided is very clear \\
&
\end{tabular}




\begin{tabular}{ll}
\hline Code & \multicolumn{1}{c}{ List of question } \\
\hline STF2 & In this SI there is ease in finding the information needed \\
STF3 & Navigation them in a satisfying interface \\
STF4 & The input method is appropriate \\
SYU1 & The organization of information on the screen is clear \\
SYU2 & This system interface is fun \\
SYU3 & I like to use this system interface \\
SYU4 & This system has all the functions and I hope to have it \\
SYU5 & Overall, I am satisfied with this system \\
\hline
\end{tabular}

\section{Research Method}

In Figure 2 below, there are a number of steps that the researcher did in answering the problems in this study.

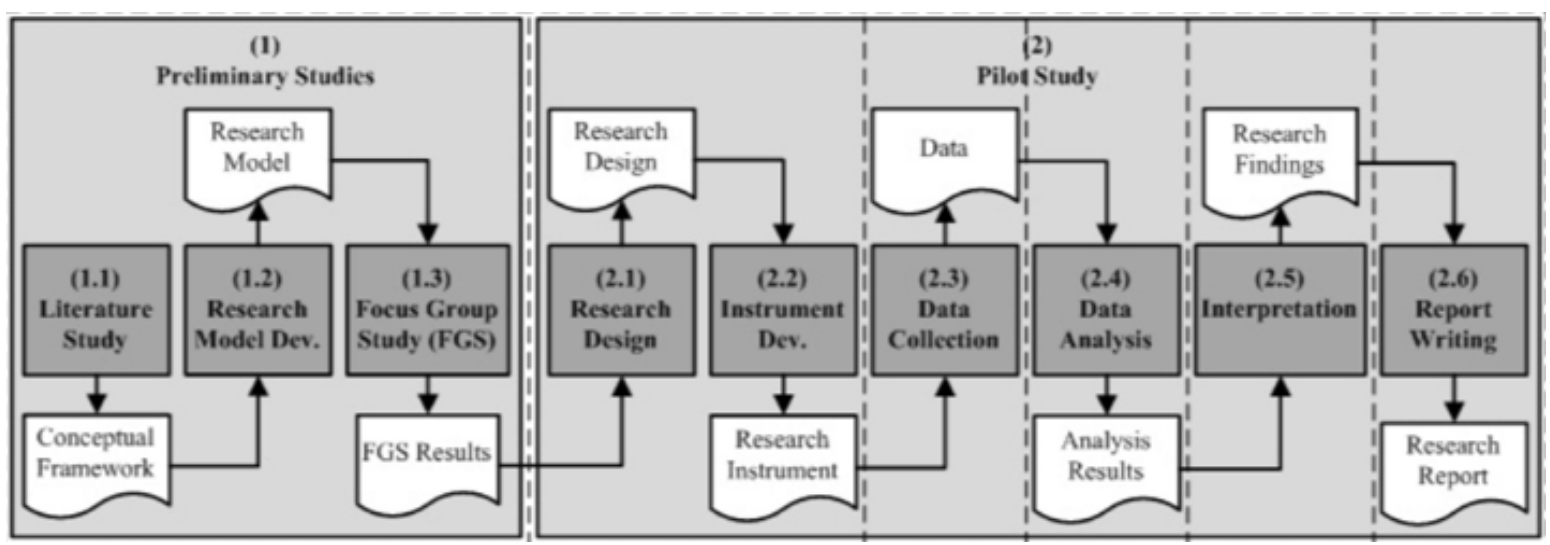

Figure 2. Research Procedure [29]

Research examines several problems from several sources as a first step (1.1). The second step of the researcher determined the research model (1.2) and conducted a Focus Group Discussion (1.3). Next, the researcher makes a research design (2.1) of the predetermined models including the research instrument (2.2). From the distribution of questionnaires based on derivatives of the Instruments (2.3), the data analysis (2.4) is carried out until the results or findings (2.5) are obtained which the researcher finally made in the form of a research report. 


\section{Result and Discussions}

\subsection{Demographic Information}

Profile of respondents based on education, position, experience and skill level in using IS. From the results of data collection on the characteristics of respondents in terms of readiness and usability in the use of information systems can provide recommendations for researchers in terms of data consistency between the data collected and the expectations of the researchers. In terms of the competencies possessed by the respondents, there were $67 \%$ who stated that they were skilled and very skilled at 33\% with knowledge about IS use at $82 \%$. There were $61 \%$ of respondents stated their readiness in the level of readiness to use IS, $21 \%$ were unprepared, and $18 \%$ were very prepared.

Regarding statements regarding the influence of readiness and usability, $48 \%$ said they were very influential, $48 \%$ said they were influential, and $3 \%$ were less influential. The results of the effect of readiness and usability based on the questions on the questionnaire asked at the beginning as part of the profile of the respondent will be used as a comparison and to find out the factors that caused their influence.

Results of Statistical Analysis

In this research, the first step is carried out at the stage of statistical analysis, namely evaluating reflective measurements that intend to evaluate internal consistency reliability using Composite Reliability, Reliability Indicators, Convergence Validity, and Discriminant Validity. Further assessment of the structural model is a step to determine whether or not significant hypotheses are based on the research model, reinforced the value of R2 from endogenous latent variables in the path model and the value of the contribution of exogenous constructs to endogenous latent variables. 


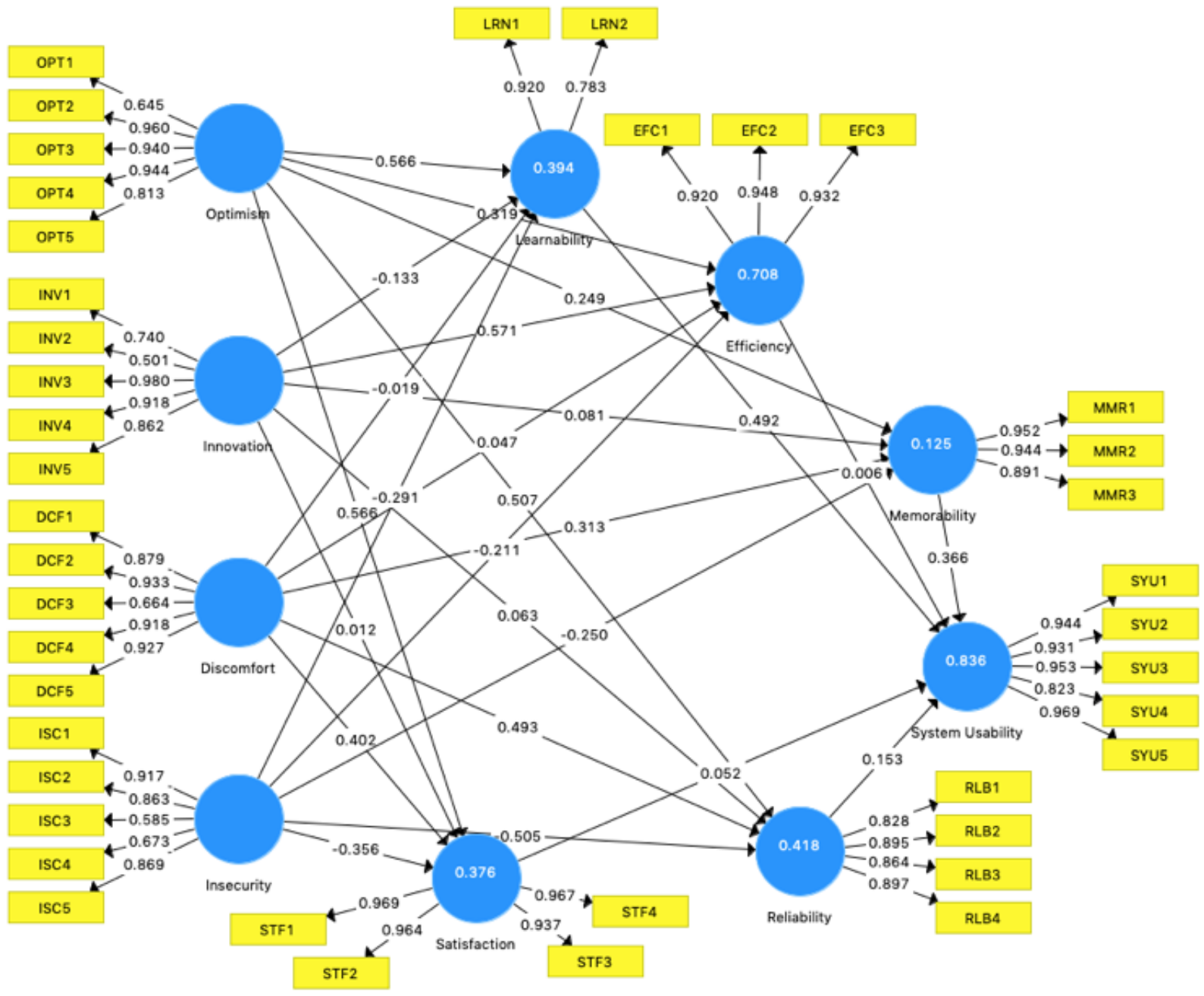

Figure 3. PLS Research Model

In Figure 3 there are indicators on several variables that have values below 0.708 , namely: OPT1, INV2, DCF3, ISC3, and ISC4, then the five indicators must be deleted and the results as in the following figure. 


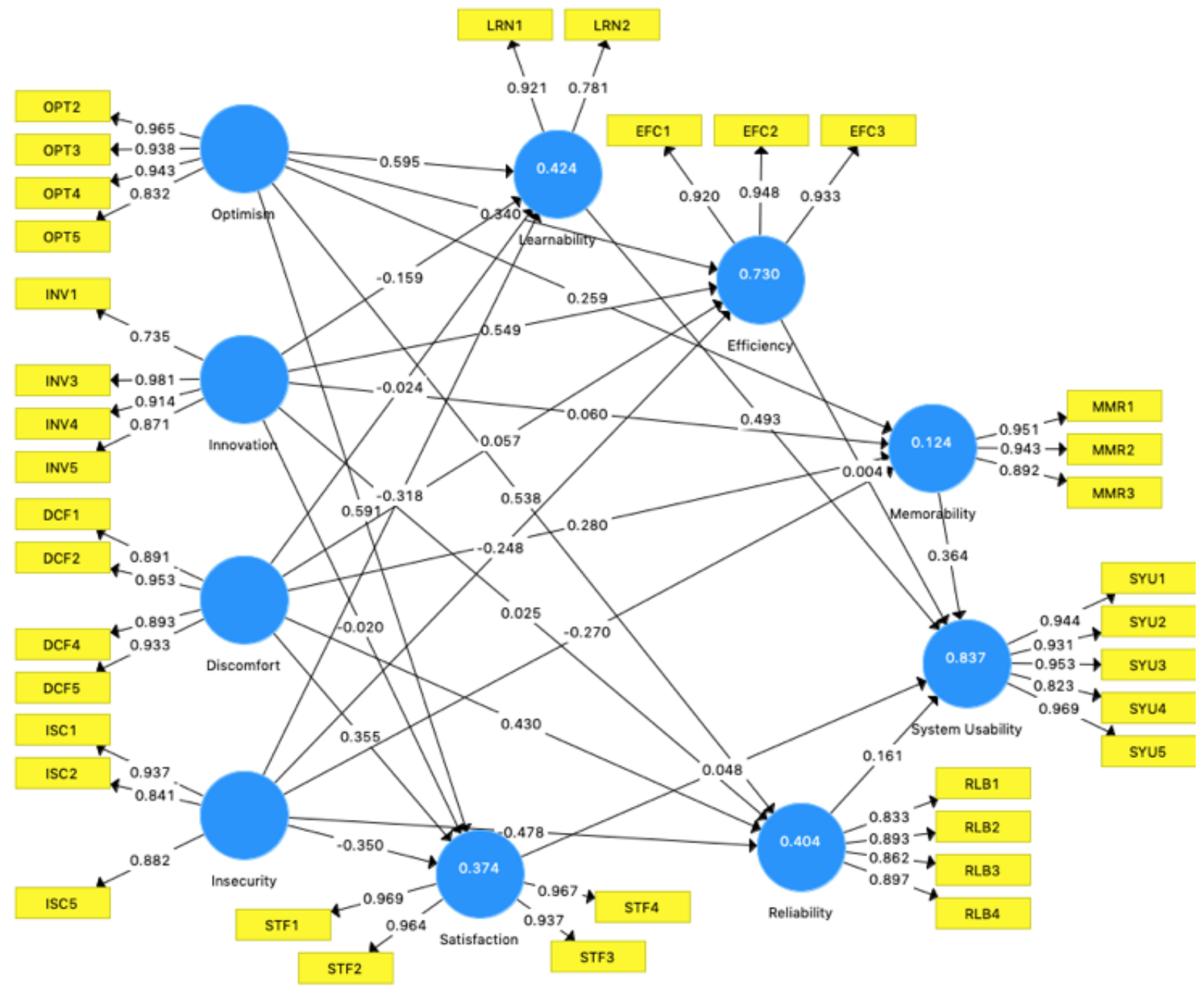

Figure 4. PLS Research model 2

Table 3. Construct Reliability and Validity

\begin{tabular}{ccccc}
\hline & $\begin{array}{c}\text { Cronbach's } \\
\text { Alpha }\end{array}$ & rho_A & Composite Reliability & $\begin{array}{c}\text { Average Variance Extracted } \\
\text { (AVE) }\end{array}$ \\
\hline DCF & 0.938 & 0.948 & 0.955 & 0.843 \\
EFC & 0.926 & 0.927 & 0.953 & 0.871 \\
INV & 0.902 & 0.946 & 0.931 & 0.774 \\
ISC & 0.865 & 0.878 & 0.918 & 0.788 \\
LRN & 0.645 & 0.743 & 0.842 & 0.729 \\
MMR & 0.921 & 0.933 & 0.950 & 0.863 \\
OPT & 0.939 & 0.943 & 0.957 & 0.848 \\
RLB & 0.894 & 0.898 & 0.927 & 0.759 \\
STF & 0.971 & 0.972 & 0.979 & 0.920 \\
SYU & 0.957 & 0.959 & 0.968 & 0.857 \\
\hline
\end{tabular}


As we can see from the table above, composite reliability for all reflective constructions is higher than 0.708 and has high internal consistency reliability.

Table 4. Outer-Loadings

\begin{tabular}{|c|c|c|c|c|c|c|c|c|c|c|}
\hline & DCF & $\mathrm{EFC}$ & INV & ISC & LRN & MMR & OPT & RLB & STF & SYU \\
\hline DCF1 & 0.891 & & & & & & & & & \\
\hline DCF2 & 0.953 & & & & & & & & & \\
\hline DCF4 & 0.893 & & & & & & & & & \\
\hline DCF5 & 0.933 & & & & & & & & & \\
\hline EFC1 & & 0.920 & & & & & & & & \\
\hline EFC2 & & 0.948 & & & & & & & & \\
\hline EFC3 & & 0.933 & & & & & & & & \\
\hline INV1 & & & 0.735 & & & & & & & \\
\hline INV3 & & & 0.981 & & & & & & & \\
\hline INV4 & & & 0.914 & & & & & & & \\
\hline INV5 & & & 0.871 & & & & & & & \\
\hline ISC1 & & & & 0.937 & & & & & & \\
\hline ISC2 & & & & 0.841 & & & & & & \\
\hline ISC5 & & & & 0.882 & & & & & & \\
\hline LRN1 & & & & & 0.921 & & & & & \\
\hline LRN2 & & & & & 0.781 & & & & & \\
\hline MMR1 & & & & & & 0.951 & & & & \\
\hline MMR2 & & & & & & 0.943 & & & & \\
\hline MMR3 & & & & & & 0.892 & & & & \\
\hline OPT2 & & & & & & & 0.965 & & & \\
\hline OPT3 & & & & & & & 0.938 & & & \\
\hline OPT4 & & & & & & & 0.943 & & & \\
\hline OPT5 & & & & & & & 0.832 & & & \\
\hline RLB1 & & & & & & & & 0.833 & & \\
\hline RLB2 & & & & & & & & 0.893 & & \\
\hline RLB3 & & & & & & & & 0.862 & & \\
\hline RLB4 & & & & & & & & 0.897 & & \\
\hline STF1 & & & & & & & & & 0.969 & \\
\hline STF2 & & & & & & & & & 0.964 & \\
\hline STF3 & & & & & & & & & 0.937 & \\
\hline STF4 & & & & & & & & & 0.967 & \\
\hline SYU1 & & & & & & & & & & 0.944 \\
\hline SYU2 & & & & & & & & & & 0.931 \\
\hline SYU3 & & & & & & & & & & 0.953 \\
\hline SYU4 & & & & & & & & & & 0.823 \\
\hline SYU5 & & & & & & & & & & 0.969 \\
\hline
\end{tabular}

From Table 4, we can see that the external loading of all indicators is above 0.7. AVEs for all models are higher than 0.5 , so convergent validity is confirmed. All external indicators load in the construct is higher than the cross load with other constructs, then discriminant validity is confirmed [30].

Determining whether the hypothesis is based on the research model that we can see in Table 5. To assess the significance of our path coefficients using a significant level of $5 \%$ and a onesided test. The significance level is 1.64 . 
Table 5. Cross loadings

\begin{tabular}{|c|c|c|c|c|c|c|c|c|c|c|}
\hline & DCF & EFC & INV & ISC & LRN & MMR & OPT & RLB & STF & SYU \\
\hline DCF1 & 0.891 & -0.166 & 0.039 & 0.506 & -0.372 & 0.012 & -0.167 & -0.015 & -0.037 & -0.234 \\
\hline DCF2 & 0.953 & $\cdot 0.207$ & $\cdot 0.017$ & 0.624 & $\cdot 0.405$ & $\cdot 0.010$ & $\cdot 0.230$ & $\cdot 0.110$ & -0.088 & -0.281 \\
\hline DCF3 & 0.893 & $\cdot 0.299$ & $\cdot 0.340$ & 0.563 & $\cdot 0.218$ & 0.142 & $\cdot 0.195$ & 0.094 & 0.122 & -0.032 \\
\hline DCF4 & 0.933 & $\cdot 0.348$ & $\cdot 0.278$ & 0.731 & $\cdot 0.303$ & $\cdot 0.021$ & $\cdot 0.306$ & $\cdot 0.033$ & -0.045 & -0.183 \\
\hline DCF5 & $\cdot 0.233$ & 0.920 & 0.803 & $\cdot 0.332$ & 0.543 & 0.307 & 0.622 & 0.506 & 0.505 & 0.434 \\
\hline EFC1 & $\cdot 0.293$ & 0.948 & 0.705 & $\cdot 0.320$ & 0.593 & 0.491 & 0.566 & 0.580 & 0.579 & 0.677 \\
\hline EFC2 & $\cdot 0.250$ & 0.933 & 0.677 & $\cdot 0.332$ & 0.585 & 0.438 & 0.715 & 0.548 & 0.580 & 0.534 \\
\hline EFC3 & $\cdot 0.104$ & 0.502 & 0.735 & $\cdot 0.232$ & 0.006 & 0.126 & 0.180 & 0.021 & 0.020 & -0.068 \\
\hline INV1 & $\cdot 0.112$ & 0.755 & 0.981 & $\cdot 0.179$ & 0.273 & 0.236 & 0.576 & 0.353 & 0.327 & 0.208 \\
\hline INV2 & $\cdot 0.226$ & 0.737 & 0.914 & $\cdot 0.289$ & 0.241 & 0.173 & 0.541 & 0.397 & 0.306 & 0.187 \\
\hline INV3 & $\cdot 0.098$ & 0.696 & 0.871 & 0.055 & 0.239 & 0.191 & 0.601 & 0.331 & 0.377 & 0.279 \\
\hline INV4 & 0.581 & $\cdot 0.320$ & $\cdot 0.194$ & 0.937 & $\cdot 0.303$ & $\cdot 0.149$ & $\cdot 0.119$ & $\cdot 0.224$ & -0.151 & -0.270 \\
\hline INV5 & 0.406 & $\cdot 0.183$ & $\cdot 0.063$ & 0.841 & $\cdot 0.246$ & $\cdot 0.089$ & $\cdot 0.104$ & $\cdot 0.375$ & -0.233 & -0.148 \\
\hline ISC2 & 0.743 & $\cdot 0.405$ & $\cdot 0.184$ & 0.882 & $\cdot 0.463$ & $\cdot 0.110$ & $\cdot 0.147$ & $\cdot 0.151$ & -0.141 & -0.333 \\
\hline ISC4 & $\cdot 0.387$ & 0.644 & 0.262 & $\cdot 0.445$ & 0.921 & 0.509 & 0.513 & 0.586 & 0.550 & 0.830 \\
\hline ISC5 & $\cdot 0.189$ & 0.356 & 0.129 & $\cdot 0.169$ & 0.781 & 0.283 & 0.429 & 0.450 & 0.427 & 0.473 \\
\hline LRN1 & 0.026 & 0.424 & 0.099 & $\cdot 0.109$ & 0.554 & 0.951 & 0.264 & 0.748 & 0.818 & 0.803 \\
\hline LRN2 & 0.053 & 0.357 & 0.226 & $\cdot 0.070$ & 0.419 & 0.943 & 0.262 & 0.744 & 0.734 & 0.707 \\
\hline MMR1 & 0.891 & -0.166 & 0.039 & 0.506 & -0.372 & 0.012 & -0.167 & -0.015 & -0.037 & -0.234 \\
\hline MMR2 & 0.953 & $\cdot 0.207$ & $\cdot 0.017$ & 0.624 & $\cdot 0.405$ & $\cdot 0.010$ & $\cdot 0.230$ & $\cdot 0.110$ & -0.088 & -0.281 \\
\hline MMR3 & 0.893 & $\cdot 0.299$ & $\cdot 0.340$ & 0.563 & $\cdot 0.218$ & 0.142 & $\cdot 0.195$ & 0.094 & 0.659 & 0.604 \\
\hline OPT1 & -0.009 & 0.462 & 0.288 & -0.196 & 0.366 & 0.892 & 0.2 & 0.597 & 0.504 & 0.271 \\
\hline OPT2 & $\cdot 0.212$ & 0.679 & 0.607 & $\cdot 0.062$ & 0.485 & 0.245 & 0.965 & 0.448 & 0.525 & 0.369 \\
\hline OPT3 & $\cdot 0.293$ & 0.657 & 0.549 & $\cdot 0.174$ & 0.569 & 0.319 & 0.938 & 0.496 & 0.458 & 0.287 \\
\hline OPT4 & $\cdot 0.239$ & 0.634 & 0.564 & $\cdot 0.152$ & 0.488 & 0.186 & 0.943 & 0.441 & 0.502 & 0.313 \\
\hline OPT5 & $\cdot 0.161$ & 0.519 & 0.401 & $\cdot 0.130$ & 0.492 & 0.205 & 0.832 & 0.505 & 0.881 & 0.823 \\
\hline RLB1 & $\cdot 0.095$ & 0.633 & 0.361 & $\cdot 0.250$ & 0.636 & 0.802 & 0.447 & 0.833 & 0.723 & 0.616 \\
\hline RLB2 & $\cdot 0.158$ & 0.522 & 0.388 & $\cdot 0.299$ & 0.507 & 0.527 & 0.528 & 0.893 & 0.773 & 0.572 \\
\hline RLB3 & $\cdot 0.044$ & 0.397 & 0.200 & $\cdot 0.178$ & 0.510 & 0.591 & 0.507 & 0.862 & 0.787 & 0.691 \\
\hline RLB4 & 0.204 & 0.459 & 0.257 & $\cdot 0.214$ & 0.477 & 0.677 & 0.317 & 0.897 & 0.969 & 0.752 \\
\hline STF1 & 0.012 & 0.552 & 0.285 & $\cdot 0.178$ & 0.556 & 0.751 & 0.507 & 0.870 & 0.964 & 0.770 \\
\hline STF2 & $\cdot 0.058$ & 0.569 & 0.284 & $\cdot 0.232$ & 0.638 & 0.810 & 0.521 & 0.898 & 0.937 & 0.701 \\
\hline STF3 & $\cdot 0.056$ & 0.588 & 0.354 & $\cdot 0.182$ & 0.499 & 0.730 & 0.546 & 0.850 & 0.967 & 0.739 \\
\hline STF4 & 0.022 & 0.575 & 0.331 & $\cdot 0.149$ & 0.526 & 0.769 & 0.503 & 0.884 & 0.735 & 0.944 \\
\hline SYU1 & $\cdot 0.149$ & 0.477 & 0.073 & $\cdot 0.238$ & 0.709 & 0.773 & 0.280 & 0.731 & 0.739 & 0.931 \\
\hline SYU2 & $\cdot 0.296$ & 0.587 & 0.213 & $\cdot 0.312$ & 0.733 & 0.689 & 0.352 & 0.734 & 0.698 & 0.953 \\
\hline SYU3 & $\cdot 0.261$ & 0.589 & 0.192 & $\cdot 0.291$ & 0.739 & 0.694 & 0.288 & 0.660 & 0.618 & 0.823 \\
\hline SYU4 & $\cdot 0.097$ & 0.396 & 0.156 & $\cdot 0.161$ & 0.775 & 0.581 & 0.323 & 0.696 & 0.777 & 0.969 \\
\hline SYU5 & $\cdot 0.154$ & 0.670 & 0.307 & $\cdot 0.332$ & 0.744 & 0.789 & 0.321 & 0.801 & 0.659 & 0.604 \\
\hline
\end{tabular}


Table 6. Assessment of the significance of path coefficients

\begin{tabular}{ccccccc}
\hline & $\begin{array}{c}\text { Original } \\
\text { Sample }(\mathrm{O})\end{array}$ & $\begin{array}{c}\text { Sample } \\
\text { Mean }(\mathrm{M})\end{array}$ & $\begin{array}{c}\text { Standard } \\
\text { Deviation } \\
\text { (STDEV) }\end{array}$ & $\begin{array}{c}\text { T Statistics } \\
(\mid \mathrm{O} / \text { STDEV } \mid)\end{array}$ & P Values & Results \\
\hline DCF -> EFC & 0.057 & -0.028 & 0.273 & 0.210 & 0.834 & Not significant \\
DCF -> LRN & -0.024 & -0.047 & 0.312 & 0.077 & 0.939 & Not significant \\
DCF -> MMR & 0.280 & 0.180 & 0.367 & 0.764 & 0.445 & Not significant \\
DCF -> RLB & 0.430 & 0.308 & 0.323 & 1.331 & 0.184 & Not significant \\
DCF -> STF & 0.355 & 0.245 & 0.309 & 1.150 & 0.251 & Not significant \\
EFC -> SYU & 0.004 & 0.000 & 0.193 & 0.018 & 0.985 & Not significant \\
INV -> EFC & 0.549 & 0.484 & 0.182 & 3.025 & 0.003 & Significant \\
INV -> LRN & -0.159 & -0.151 & 0.270 & 0.590 & 0.556 & Not significant \\
INV -> MMR & 0.060 & 0.050 & 0.334 & 0.180 & 0.858 & Not significant \\
INV -> RLB & 0.025 & -0.024 & 0.237 & 0.103 & 0.918 & Not significant \\
INV -> STF & -0.020 & -0.061 & 0.213 & 0.092 & 0.927 & Not significant \\
ISC -> EFC & -0.248 & -0.090 & 0.289 & 0.858 & 0.391 & Not significant \\
ISC -> LRN & -0.318 & -0.138 & 0.369 & 0.861 & 0.390 & Not significant \\
ISC -> MMR & -0.270 & -0.193 & 0.389 & 0.696 & 0.487 & Not significant \\
ISC -> RLB & -0.478 & -0.301 & 0.415 & 1.151 & 0.250 & Not significant \\
ISC -> STF & -0.350 & -0.238 & 0.345 & 1.013 & 0.311 & Not significant \\
LRN -> SYU & 0.493 & 0.447 & 0.274 & 1.798 & 0.073 & Significant \\
MMR -> SYU & 0.364 & 0.320 & 0.295 & 1.234 & 0.218 & Not significant \\
OPT -> EFC & 0.340 & 0.382 & 0.194 & 1.754 & 0.080 & Significant \\
OPT -> LRN & 0.595 & 0.513 & 0.390 & 1.528 & 0.127 & Not significant \\
OPT -> MMR & 0.259 & 0.277 & 0.316 & 0.819 & 0.413 & Not significant \\
OPT -> RLB & 0.538 & 0.548 & 0.276 & 1.948 & 0.052 & Significant \\
OPT -> STF & 0.591 & 0.600 & 0.281 & 2.104 & 0.036 & Significant \\
RLB -> SYU & 0.161 & 0.126 & 0.287 & 0.561 & 0.575 & Not significant \\
STF -> SYU & 0.048 & 0.093 & 0.506 & 0.094 & 0.925 & Not significant \\
\hline
\end{tabular}

Table 7. R-Square

\begin{tabular}{ccc}
\hline & R Square & R Square Adjusted \\
\hline EFC & 0.730 & 0.638 \\
LRN & 0.424 & 0.324 \\
MMR & 0.124 & -0.029 \\
RLB & 0.404 & 0.300 \\
STF & 0.374 & 0.265 \\
SYU & 0.837 & 0.800 \\
\hline
\end{tabular}

The R2 value of the endogenous construct of each System Efficiency and System Usability is substantial, while the endogenous Memorability construct is weak. For endogenous constructs, Learnability, Reliability, and Satisfaction, each is moderate (Table 7). Meanwhile, from Table 8, we can see all the contributions of exogenous constructs to their endogenous latent variables [30]. 
Table 8. F-Square

\begin{tabular}{|c|c|c|c|c|c|c|c|c|c|c|}
\hline & $\mathrm{DCF}$ & $\mathrm{EFC}$ & INV & ISC & LRN & MMR & OPT & RLB & STF & SYU \\
\hline DCF & & 0.006 & & & 0.001 & 0.047 & & 0.165 & 0.107 & \\
\hline EFC & & & & & & & & & & 0.000 \\
\hline INV & & 0.730 & & & 0.029 & 0.003 & & 0.001 & 0.000 & \\
\hline ISC & & 0.124 & & & 0.096 & 0.046 & & 0.209 & 0.107 & \\
\hline LRN & & & & & & & & & & 0.776 \\
\hline MMR & & & & & & & & & & 0.289 \\
\hline OPT & & & & & & & & & & \\
\hline RLB & & 0.271 & & & 0.389 & 0.048 & & 0.308 & 0.354 & \\
\hline STF & & & & & & & & & & 0.024 \\
\hline SYU & & & & & & & & & & 0.002 \\
\hline
\end{tabular}

The f-square value of the exogenous DCF construction towards endogenous latent variables EFC, small LRN and towards medium endogenous MMR and STF, while endogenous towards large RLB. For the exogenous construction of INV for large EFC endogenous latent variables, the endogenous MMR, RLB, and STF are small, while the endogenous LRN is medium. In the exogenous construction of ISC towards the endogenous latent variables of large RLB, while the endogenous EFC, LRN, MMR, and STF are being. For exogenous construction of RLB for medium and endogenous MMR latent variables, EFC, LRN, RLB, and STF are large. Exogen $\mathrm{SYU}$ as an output variable from combining the f-square value model from the endogenous construction of small and endogenous EFC and SYU STF, while endogenous LRN and MMR are large.

\section{Conclusion}

From the results of the research presented, the factors that influence the use of information systems from the variables of readiness and usability (hybrid models), namely: innovation on efficiency, ease of learning on system usability, optimism on efficiency, optimism on efficiency, optimism on reliability, and optimism to satisfaction. When looking at the initial statement according to respondents that $48 \%$ stated that it was very influential and $48 \%$ said it was influential, and based on the results of statistical analysis of the factors that influenced it, researchers assessed that in the use of information systems it was ensured that innovation and optimism were important in using the system information. To further strengthen this research, of course, other research must try to apply it to different objects with different characteristics of the respondent's profile. 


\section{References}

[1] M. Kirwan, M. J. Duncan, C. Vandelanotte, W. K. J. H. E. Mummery, and Behavior, "Design, development, and formative evaluation of a smartphone application for recording and monitoring physical activity levels: the 10,000 Steps "iStepLog"," vol. 40, no. 2, pp. 140-151, 2013.

[2] M. Kirwan, M. J. Duncan, C. Vandelanotte, and W. K. J. J. o. m. I. r. Mummery, "Using smartphone technology to monitor physical activity in the 10,000 Steps program: a matched case-control trial," vol. 14, no. 2, 2012.

[3] J. E. R. McMillan, W. B. Glisson, and M. Bromby, "Investigating the increase in mobile phone evidence in criminal activities," in System sciences (hicss), 2013 46th hawaii international conference on, 2013, pp. 4900-4909: IEEE.

[4] S. Stieglitz and T. J. M. Q. E. Brockmann, "Increasing organizational performance by transforming into a mobile enterprise," vol. 11, no. 4, 2012.

[5] D. Tapscott and A. Caston, Paradigm Shift: The New Promise of Information Technology. ERIC, 1993.

[6] D. Yuniarto, A. Subiyakto, E. Firmansyah, D. Herdiana, M. Suryadi, and A. A. Rahman, "Integrating the Readiness and Usability Models for Assessing the Information System Use," The 6th International Conference on Cyber and IT Service Management (CITSM 2018) Medan, August 7-9, 2018, 2018.

[7] S. J. Elias et al., "Face recognition attendance system using Local Binary Pattern (LBP)," vol. 8, no. 1, pp. 239-245, 2019.

[8] Y. Han et al., "Self-powered gait pattern-based identity recognition by a soft and stretchable triboelectric band," vol. 56, pp. 516-523, 2019.

[9] B. V. Kranthi and B. Surekha, "Real-Time Facial Recognition Using Deep Learning and Local Binary Patterns," in Proceedings of International Ethical Hacking Conference 2018, 2019, pp. 331-347: Springer.

[10] R. Agarwal, R. Jain, R. Regunathan, and C. P. Kumar, "Automatic Attendance System Using Face Recognition Technique," in Proceedings of the 2nd International Conference on Data Engineering and Communication Technology, 2019, pp. 525-533: Springer.

[11] D. Sagar and M. K. Narasimha, "Development and Simulation Analysis of a Robust Face Recognition Based Smart Locking System," in Innovations in Electronics and Communication Engineering: Springer, 2019, pp. 3-14.

[12] D. M. V. J. I. J. o. C. S. R. Salac, "PRESENT: An Android-Based Class Attendance Monitoring System Using Face Recognition Technology," vol. 2, no. 3, pp. 102-115, 2019. [13] A. Parasuraman and C. L. Colby, "An Updated and Streamlined Technology Readiness Index: TRI 2.0," Journal of Service Research, vol. 18, no. 1, pp. 59-74, 2015.

[14] A. Parasuraman and C. L. Colby, "An Updated and Streamlined Technology Readiness Index: TRI 2.0," Journal of Service Research, vol. 18, no. 1, pp. 59-74, 2014.

[15] J. Nielsen, "Usability Metrics (2001)," ed, 2017.

[16] S.-C. Chen and H. H. Chen, "The influence of technology readiness on the theory of planned behavior with self-service technologies," WMSCI 2008 - The 12th World MultiConference on Systemics, Cybernetics and Informatics, Jointly with the 14th International Conference on Information Systems Analysis and Synthesis, ISAS 2008 - Proc., vol. 6, no. 40, pp. 85-90, 2008.

[17] J. Coughlan, "B2B Technology Readiness in SME Retailing," no. May, 2012. 
[18] K. M. Elliott, M. C. Hall, and J. G. Meng, "Student Technology Readiness And Its Impact On Cultural Competency," College Teaching Methods \& Styles Journal, vol. 4, no. 6, pp. 11-22, 2008.

[19] N. Erdoğmu and M. Esen, "An investigation of the effects of technology readiness on technology acceptance in e-HRM," Procedia - Social and Behavioral Sciences, vol. 24, no. December 2011, pp. 487-495, 2011.

[20] K. M. Kuo, C. F. Liu, and C. C. Ma, "An investigation of the effect of nurses' technology readiness on the acceptance of mobile electronic medical record systems," BMC Med Inform Decis Mak, vol. 13, p. 88, Aug 122013.

[21] N. Larasati, Widyawan, and P. I. Santosa, "Technology Readiness and Technology Acceptance Model in New Technology Implementat ion Process in Low Technology SME s," International Journal of Innovation, Management and Technology, vol. 8, no. 2, pp. 113-117, 2017.

[22] N. M. Noh, H. M. A. Mustafa, and C. N. C. Ahmad, "Predictive Relationship between Technology Acceptance Readiness and the Intention to Use Malaysian EduwebTV among Library and Media Teachers," Procedia - Social and Behavioral Sciences, vol. 116, pp. 144-148, 2014.

[23] A. Subiyakto and A. R. Bin Ahlan, "A coherent framework for understanding critical success factors of ICT project environment," International Conference on Research and Innovation in Information Systems, ICRIIS, vol. 2013, pp. 342-347, 2013.

[24] M. Jaafar, T. Ramayah, A. R. Abdul-Aziz, and B. Saad, "Technology readiness among managers of Malaysian construction firms," Engineering, Construction and Architectural Management, vol. 14, no. 2, pp. 180-191, 2007.

[25] J. Nielsen, "Usability 101 : Introduction to Usability Why Usability is Important How to Improve Usability," Focus, pp. 1-4, 2006.

[26] F. D. Davis, "Perceived Usefulness, Perceived Ease of Use, and User Acceptance of Information Technology," MIS Quarterly, vol. 13, no. 3, p. 319, 1989.

[27] M. Lescevica, E. Ginters, and R. Mazza, "Unified theory of acceptance and use of technology (UTAUT) for market analysis of FP7 CHOReOS products," Procedia Computer Science, vol. 26, no. December, pp. 51-68, 2013.

[28] A. Subiyakto, "Development of the Readiness and Success Model for Assessing the Information System Integration," pp. 1-10, 2017.

[29] A. Subiyakto, A. R. Ahlan, M. Kartiwi, and S. J. Putra, "Measurement of the information system project success of the higher education institutions in Indonesia: a pilot study," International Journal of Business Information System, vol. 23, no. 2, pp. 229-247, 2016.

[30] J. F. Hair Jr, G. T. M. Hult, C. Ringle, and M. Sarstedt, A primer on partial least squares structural equation modeling (PLS-SEM). Sage Publications, 2016. 